\title{
Analysis of the add-on effect of $\alpha$-glucosidase inhibitor, acarbose in insulin therapy: A pilot study
}

\author{
FENG-FEI LI ${ }^{1}$, LI-YUAN FU ${ }^{2}$, XIAO-HUA XU ${ }^{1}$, XIAO-FEI SU ${ }^{1}$, JIN-DAN WU ${ }^{1}$, LEI YE ${ }^{3}$ and JIAN-HUA MA ${ }^{1}$ \\ ${ }^{1}$ Department of Endocrinology, Nanjing First Hospital, Nanjing Medical University, Nanjing, Jiangsu 210012; \\ ${ }^{2}$ Nanjing University of Chinese Medicine, Nanjing, Jiangsu 210023, P.R. China; \\ ${ }^{3}$ National Heart Research Institute Singapore, National Heart Centre Singapore, Singapore 169609, Republic of Singapore
}

Received April 1, 2016; Accepted July 6, 2016

DOI: $10.3892 /$ br.2016.744

\begin{abstract}
The aim of the present study was to evaluate the add-on effect of acarbose therapy in oxidative stress, and the lipid and inflammatory profiles of patients with type 2 diabetes mellitus (T2DM) treated with insulin. This was an open and unblended study. Patients $(n=134)$ with T2DM (haemoglobin $\mathrm{A}_{1 \mathrm{c}}$ range, 9.0-12.0\%) were recruited. After continuous subcutaneous insulin infusion for 7 days for initial rapid correction of hyperglycaemia, a premixed insulin titration period (duration, 4-6 days) subsequently followed. Patients were then randomized (1:1) into two groups as follows: An acarbose plus pre-mixed 30/70 insulin group or a pre-mixed $30 / 70$ insulin only group; each group received treatment for 2 weeks. Plasma high-sensitivity C-reactive protein (Hs-CRP), 8-iso-prostaglandin $\mathrm{F}_{2 \alpha}$ (8-iso $\mathrm{PGF}_{2 \alpha}$ ), tumor necrosis factor- $\alpha$ (TNF- $\alpha$ ), interleukin (IL)-1 $\beta$, and IL-6 levels were measured before and after therapy. Patients that received acarbose plus insulin demonstrated greater reduction in 8-iso $\mathrm{PGF}_{2 \alpha}$, Hs-CRP, TNF- $\alpha$, IL- $1 \beta$ and IL- 6 levels when compared with the insulin only patients. Thus, acarbose add-on insulin therapy was identified to be associated with greater improvements in oxidative stress and inflammation in patients with T2DM when compared with those that received insulin only therapy.
\end{abstract}

\section{Introduction}

Acarbose is an $\alpha$-glucosidase inhibitor. It slows the breakdown of carbohydrates in the gut, and delays absorption of carbohydrates by inhibition of a-amylase and $\alpha$-glucosidase activities, which reduces post-prandial hyperglycemia $(1,2)$. The reduction of blood glucose concentration is accompanied by a decreased

Correspondence to: Professor Jian-Hua Ma, Department of Endocrinology, Nanjing First Hospital, Nanjing Medical University, 32 Gongqingtuan, Nanjing, Jiangsu 210012, P.R. China

E-mail: majianhua196503@126.com

Key words: acarbose, oxidative stress, inflammation, type 2 diabetes mellitus insulin demand and increased insulin sensitivity in type 2 diabetes mellitus (T2DM) (3). Recently, by using a continuous glucose monitoring system (CGMS), further improvements in glucose fluctuation in T2DM patients treated with pre-mixed insulin therapy were observed (4). Microvascular and macrovascular complications are mainly $(5,6)$ or partially $(6,7)$ caused by hyperglycemia. Monnier et al (8) reported that acute glucose fluctuations during postprandial periods were crucial in oxidative stress. The rapid rise in postprandial blood glucose concentrations induces an overproduction of peroxynitrite and nitrotyrosine $(8,9)$. As demonstrated by clinical trials, acarbose has been reported to improve postprandial endothelial dysfunction in newly diagnosed T2DM patients (10), as well as decreasing the lipid peroxidation and platelet activation in patients with T2DM (11). Furthermore, in patients with impaired glucose tolerance, acarbose was associated with a $49 \%$ relative risk reduction in the development of cardiovascular events (12).

A previous study demonstrated that exogenous hyperinsulinemia increases the activation of $\mathrm{NAD}(\mathrm{P}) \mathrm{H}$ in the rat aortic endothelium (13). However, at normal concentrations of insulin, the effect of insulin on activating oxidative stress is considered to be controversial (14). As insulin therapy is used for treating patients with T2DM worldwide, the administration of a combination of acarbose and insulin therapy is proposed.

Therefore an open and unblended study was performed to investigate the add-on effect of acarbose on oxidative stress, and the lipid and inflammatory profiles in patients with T2DM treated with insulin.

\section{Materials and methods}

Patients. One hundred and thirty four patients (male: female, 67:67) with newly diagnosed T2DM were admitted to Nanjing First Hospital (Nanjing, China) between January, 2014 and May, 2015. Patients were aged 18-75 years with body mass index (BMI; calculated as weight in kilograms divided by the square of their height in meters), $18-40 \mathrm{~kg} / \mathrm{m}^{2}$ and hemoglobin $\mathrm{A}_{1 \mathrm{c}}\left(\mathrm{HbA}_{\mathrm{lc}}\right)$ range, 9.0-12.0\%. Patients were excluded if they had acute or severe chronic diabetic complications, serious systemic disease or poor medication compliance. Patients with known cancers, known allergies to insulin or acarbose, or deemed not suitable to participate following an assessment 
by the researchers were excluded $(15,16)$. The patients received therapy via continuous subcutaneous insulin infusion (CSII) for initial rapid correction of hyperglycaemia (defined as fasting plasma glucose between 7.0 and $8.0 \mathrm{mmol} / \mathrm{l}$ ). Total daily doses for CSII were calculated as $0.4-0.6 \mathrm{IU} / \mathrm{kg}$, and $50 \%$ of the total daily dose was administered as boluses with three meals at a fixed rate; the remaining insulin was administered over $24 \mathrm{~h}$. Insulin doses were subsequently adapted according to blood glucose values that were obtained by self-monitoring. After rapid correction of hyperglycaemia, a premixed insulin titration period (duration, 4-6 days) subsequently followed. Patients were then randomized (1:1) into two groups: The acarbose plus insulin isophane protamine recombinant human insulin 30/70 (pre-mixed 30/70 insulin; twice-daily) group and a pre-mixed 30/70 insulin (twice-daily) only group. The initial pre-mixed $30 / 70$ insulin doses were calculated according to the insulin dose used for the CSII, and subsequently adapted according to fasting capillary blood glucose and capillary blood glucose at $2 \mathrm{~h}$ after each of three meals (15). Investigators titrated the insulin doses on an individual patient basis with the titration algorithm (if the fasting blood glucose level was $<4.4 \mathrm{mmol} / \mathrm{l}$, the insulin dose was reduced by 2 units; if the fasting blood glucose level was within 4.4-6.1 $\mathrm{mmol} / 1$, the insulin dose was unchanged; if the fasting blood glucose level was within 6.2-7.8, 7.9-10.0, and $>10.0 \mathrm{mmol} / 1$, the insulin dose was subsequently increased by 2,4 , and 6 units, respectively). Pre-mixed insulin doses were unchanged and recorded if euglycemic control was achieved for two consecutive days. Patients were subsequently randomized to receive acarbose $(100 \mathrm{mg}$, t.i.d; Glucobay; Bayer AG, Leverkusen, Germany) plus pre-mixed 30/70 (twice-daily) or pre-mixed insulin 30/70 (twice-daily) only. Treatment was maintained for 2 weeks. CGMS data were obtained using Medtronic MiniMed CGMS Gold (Medtronic Incorporated, Northridge, USA) for at least 3 days on completion of 2 weeks randomized treatment (17). All patients were subjected to 3 consecutive days of CGMS use in the hospital by a specialist nurse. Briefly, the CGMS sensor was subcutaneously embedded at day 0 around 16:00-17:00 PM. The patients continued with the sensor for 3 consecutive days if use of the CGMS was going well. Subjects were instructed to keep the sensor fixed and waterproof. The study nurse input a minimum of four calibration readings per day. At day 3, at around 16:00-17:00 PM, subjects had the sensor removed and the CGMS data were saved by the investigator. The 24-h mean amplitude of glycemic excursions (MAGE), the 24-h mean blood glucose (MBG), the percentage time duration $(\%)$ and the incremental area under the curve (AUC) of plasma glucose $>10.0$ and $<3.9 \mathrm{mmol} / 1$ was calculated, and hypoglycemia episodes were also recorded. MAGE was calculated for each patient by measuring the arithmetic mean of the ascending and descending excursions between consecutive peaks and nadirs for the same $24 \mathrm{~h}$ period, only absolute excursion values $>1$ standard deviation (SD) were considered (18).

Ethical approval. The current study was approved by the ethics committee of Nanjing First Hospital (Nanjing, China), and was in accordance with the 1964 Helsinki declaration and its later amendments or comparable ethical standards. Written informed consent was obtained from the patients prior to participation in the present study.
Assays. The following plasma parameters were measured at baseline and upon completion of the study: Fasting plasma glucose, fasting plasma insulin, lipid profile, high-sensitivity $\mathrm{C}$ reactive protein (Hs-CRP), 8-iso prostaglandin $\mathrm{F}_{2 \alpha}$ (8-iso $\mathrm{PGF}_{2 \alpha}$ ), tumor necrosis factor- $\alpha$ (TNF- $\alpha$ ), interleukin (IL)-1 $\beta$, IL-6, adiponectin (APN) and leptin. Plasma glucose concentrations were measured the day before and after therapy withdrawal using an Accu-Chek ${ }^{\circledR}$ Active glucometer (Roche Diagnostics GmbH, Mannheim, Germany). Fasting plasma insulin was determined using an insulin radioimmunoassay kit according to the manufacturer's instructions (Beijing Beifang Technology Co., Beijing, China). $\mathrm{HbA}_{1 \mathrm{c}}$ was measured using a Diastat $\mathrm{HbA}_{\mathrm{lc}}$ analyzer (Bio-Rad Laboratories, Inc., Hercules, CA, USA) at baseline. Hs-CRP was determined using radioimmunoassay kits provided by Beijing Onder High-Tech Co., Ltd. (Beijing, China) according to the manufacturer's instructions. The plasma 8-iso $\mathrm{PGF}_{2 \alpha}$ level was measured using an enzyme immunoassay method according to the manufacturer's instructions (Cayman Chemical Co., Ann Arbor, MI, USA) (19). TNF- $\alpha$ was measured using the human-specific Milliplex map kit (EMD Millipore, St. Charles, MO, USA) according to the manufacturer's instructions. IL-1 $\beta$ was determined using enzyme-linked immunosorbent assay (ELISA) procedures (Orgenium Laboratories, Helsinki, Finland) and IL-6 was determined using commercially available ELISA kits (R\&D Systems, Minneapolis, MN, USA) according to manufacturer's instructions. APN and leptin were measured using enzyme immunoassay kits (from R\&D Systems, Inc., Minneapolis, MN, USA and Mercodia AB, Uppsala, Sweden, respectively) according to the manufacturer's instructions.

Statistical analysis. Statistical analysis was performed using SPSS software (version 17.0; SPSS, Inc., Chicago, IL, USA). The Shapiro-Wilk test was used to assess the distribution of data. Normally distributed and continuous variables are presented as means \pm SD. Non-normally distributed variables are presented as medians (interquartile range) and were logarithmically transformed prior to analysis. The independent samples $t$-test was used to compare each group difference and Bonferroni correction was subsequently performed, with a significance level of $5 \%$.

\section{Results}

Patient characteristics. The patients $(n=134)$ were randomized into each of the two treatment groups. Their demographic characteristics and history of T2DM are presented in Table I. The two groups were well matched in terms of age, gender and BMI with no significant differences identified between the two groups.

Glucose control. Table II compares the 24-h mean glucose levels, and the percentage of time of significant hyperglycemia (glucose, $>10 \mathrm{mmol} / \mathrm{l}$ ) and significant hypoglycemia (glucose, $<3.9 \mathrm{mmol} / \mathrm{l}$ ) between the two groups. The differences between the acarbose plus insulin group and the monotherapy group were not statistically significant between the 24-h MBG, 24-h MBG SD, the hyperglycemic and hypoglycemic episodes, or the hyperglycemic and hypoglycemic duration (Table II). However, patients in the acarbose plus insulin 
Table I. Baseline characteristics of the study population $(\mathrm{n}=134)$.

\begin{tabular}{lccc}
\hline Characteristic & Acarbose + & Acarbose - & P-value \\
\hline Patients (n) & 68 & 66 & - \\
Gender (male/female) & $35 / 33$ & $32 / 34$ & - \\
Age (years) & $65.75 \pm 4.35$ & $66.33 \pm 7.66$ & 0.926 \\
Body weight $(\mathrm{kg})$ & $60.15 \pm 10.33$ & $62.15 \pm 10.86$ & 0.845 \\
Body mass index $\left(\mathrm{kg} / \mathrm{m}^{2}\right)$ & $23.63 \pm 3.93$ & $24.23 \pm 2.21$ & 0.729 \\
$\mathrm{HbA}_{1 \mathrm{c}}(\%)$ & $9.66 \pm 1.90$ & $9.79 \pm 1.19$ & 0.721
\end{tabular}

Acarbose + , acarbose add-on insulin therapy group; Acarbose -, insulin monotherapy group. $\mathrm{HbA}_{1 \mathrm{c}}$, haemoglobin $\mathrm{A}_{1 \mathrm{c}}$. Data are presented as means \pm standard deviation.

Table II. Glucose fluctuation parameters in the two groups upon completion of the follow-up period.

\begin{tabular}{lccc}
\hline Parameter & Acarbose + & Acarbose - & P-value \\
\hline Insulin dose/day (IU) & $36.43 \pm 17.16$ & $37.5 \pm 12.40$ & 0.891 \\
24-h MBG (mmol/l) & $8.2 \pm 1.39$ & $8.4 \pm 1.64$ & 0.711 \\
24-h MBG SD (mmol/l) & $2.34 \pm 0.67$ & $2.68 \pm 1.26$ & 0.384 \\
Hyperglycemic episodes, $(\mathrm{n}=16)$ & $3.11 \pm 1.69$ & $3.36 \pm 2.17$ & 0.739 \\
Hypoglycemic episodes, $(\mathrm{n}=8)$ & $2.09 \pm 1.68$ & $2.38 \pm 1.81$ & 0.892 \\
Hyperglycemic duration (\%) & $28.24 \pm 25.19$ & $28.44 \pm 19.36$ & 0.963 \\
Hypoglycemic duration (\%) & $5.01 \pm 8.19$ & $7.26 \pm 12.37$ & 0.629 \\
\hline
\end{tabular}

Hyperglycemic, $>10 \mathrm{mmol} / \mathrm{l}$ glucose; hypoglycemic, $<3.9 \mathrm{mmol} / \mathrm{l}$ glucose; Data are presented as means $\pm \mathrm{SD}$. Acarbose + , acarbose add-on insulin therapy group; Acarbose -, insulin monotherapy group. MBG, mean blood glucose; SD, standard deviation.

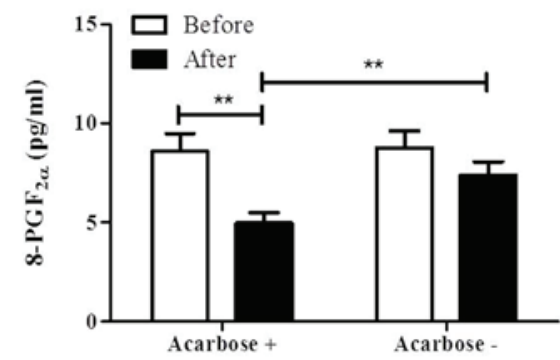

Figure 1. Plasma 8-PGF $2 \alpha$ levels in patients with type 2 diabetes mellitus before and after acarbose add-on insulin and insulin monotherapy treatment. 8-PGF ${ }_{2 \alpha}, 8$-iso-prostaglandin $\mathrm{F}_{2 \alpha}$.

group demonstrated significant decreases in the incremental AUC $>10 \mathrm{mmol} / \mathrm{l}[0.85(0.23,1.4) \mathrm{mmol} / \mathrm{l}$ per day] and MAGE $(7.50 \pm 3.28 \mathrm{mmol} / \mathrm{l})$ compared with patients in the insulin only group.

BMI, blood glucose and insulin change. The BMI of patients from the two groups was calculated at the end of therapy. BMI was almost unchanged in the two groups, with no significant difference identified between groups $(\mathrm{P}>0.05)$. Fasting blood glucose significantly improved in each group after the 2-week treatment [acarbose plus insulin group: $8.21 \pm 2.13$ to $6.98 \pm 1.53 \mathrm{mmol} / \mathrm{l}(\mathrm{P}<0.05)$; insulin only group: $8.30 \pm 2.32$ to $7.16 \pm 3.28 \mathrm{mmol} / \mathrm{l}(\mathrm{P}<0.05)]$. No significant difference in fasting blood glucose levels was identified between the two groups $(\mathrm{P}>0.05)$. Fasting insulin was assessed 2 days after completion of treatment. It was almost unchanged $(8.14 \pm 3.09$ to $8.87 \pm 4.11 \mu \mathrm{U} / \mathrm{ml} ; \mathrm{P}>0.05)$ in the acarbose plus insulin group, whereas it slightly decreased from $7.78 \pm 2.17$ to $6.71 \pm 3.34 \mu \mathrm{U} / \mathrm{ml}(\mathrm{P}>0.05)$ in the insulin only group. No statistical difference of fasting insulin concentration was identified between the two groups $(\mathrm{P}>0.05)$.

Oxidative stress. To determine the effect of co-administration of acarbose with insulin on oxidative stress in patients with T2DM, 8-PGF $2 \alpha$, a well-recognized biomarker of oxidative stress, was measured. As shown in Fig. 1, 8-PGF $2 \alpha$ was significantly decreased in the acarbose plus insulin group from $8.55 \pm 3.62$ to $4.97 \pm 2.16 \mathrm{pg} / \mathrm{ml}(\mathrm{P}<0.01)$. Although it exhibited a decreasing tendency in the insulin group $(8.79 \pm 3.58$ to $6.65 \pm 2.45 \mathrm{pg} / \mathrm{ml}$ ), no statistically significant difference was observed. Furthermore, the $8-\mathrm{PGF}_{2 \alpha}$ level of the acarbose plus insulin group was significantly lower than that of the insulin group at 2 weeks $(\mathrm{P}<0.01$; Fig. 1).

Inflammatory cytokines. Patients with T2DM have a significantly higher inflammatory score when compared with control subjects (20). Although significant decreases of inflammatory cytokines were found in the two groups, the addition of acarbose resulted in further reductions of 

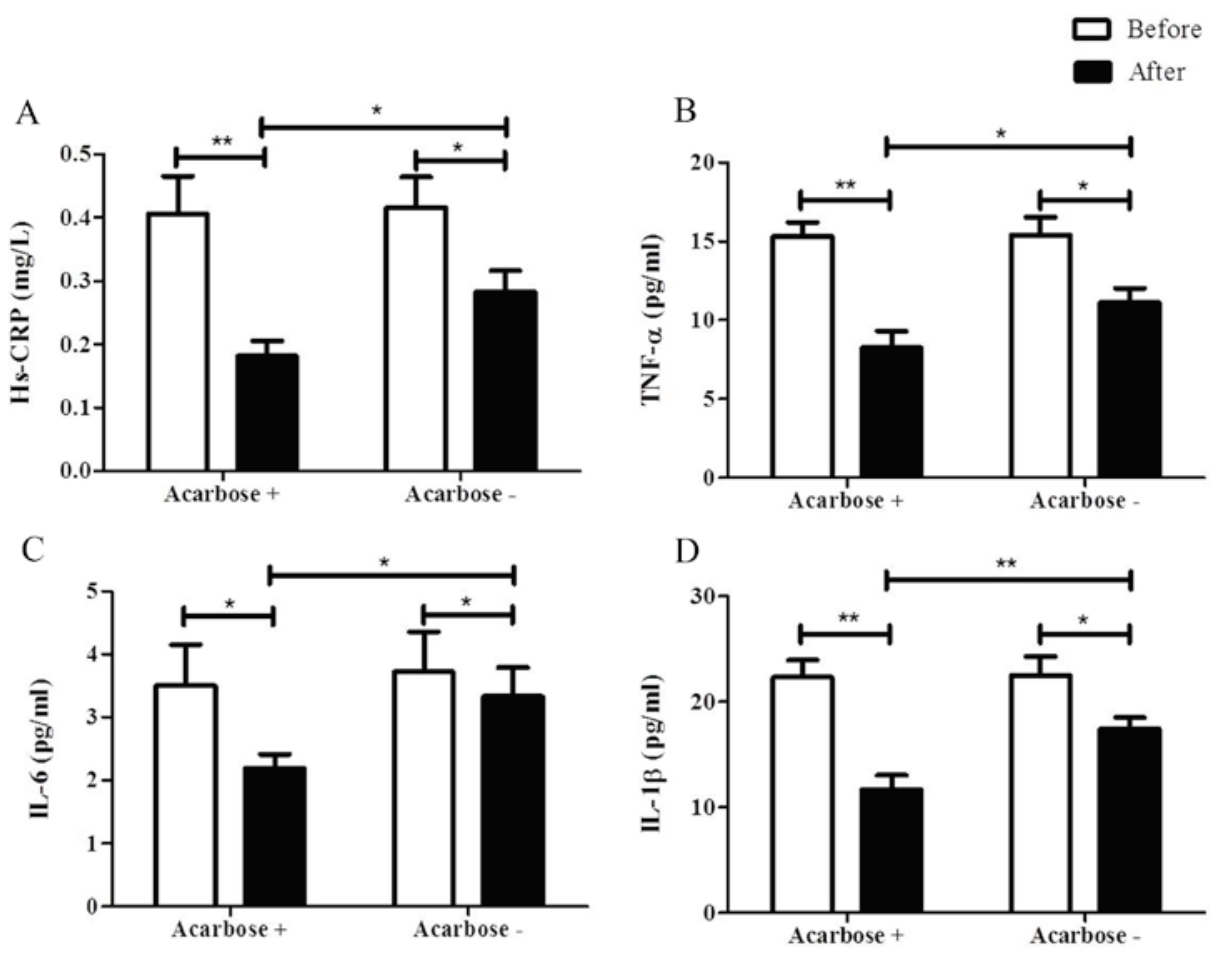

Figure 2. Plasma cytokine levels in patients with type 2 diabetes mellitus before and after therapy. (A) Hs-CRP, (B) TNF- $\alpha$, (C) IL-6 and (D) IL-1 $\beta$. Data are presented as means \pm standard deviation. Hs-CRP, high-sensitivity C-reactive protein; TNF- $\alpha$, tumor necrosis factor- $\alpha$; IL, interleukin.
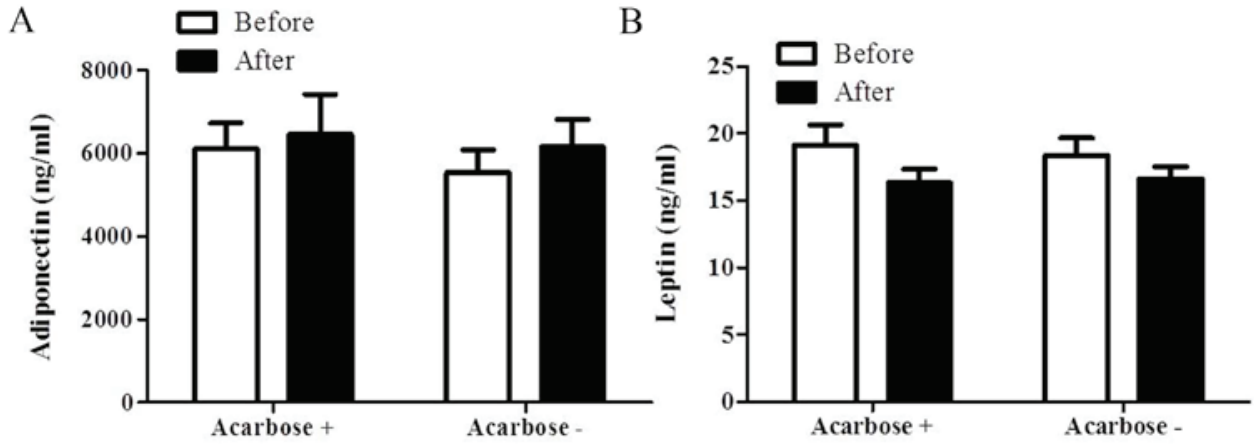

Figure 3. Plasma adipocytokine levels in patients with type 2 diabetes mellitus before and after therapy. (A) Adiponectin and (B) leptin.

inflammatory cytokine levels, when compared with the insulin only group at 2 weeks. The Hs-CRP level of the acarbose plus insulin group decreased from $0.41 \pm 0.24$ to $0.18 \pm 0.10 \mathrm{mg} / 1(\mathrm{P}<0.05)$. This was also observed in the insulin only group $(0.42 \pm 0.20$ to $0.28 \pm 0.14 \mathrm{mg} / 1 ; \mathrm{P}<0.05)$. Notably, the Hs-CRP level of the acarbose plus insulin group was significantly lower than that of the insulin only group at 2 weeks ( $\mathrm{P}<0.05$; Fig. 2A).

The TNF- $\alpha$ level was significantly reduced in the two groups at 2 weeks after treatment. It significantly reduced from $14.59 \pm 4.56$ to $8.13 \pm 4.56 \mathrm{pg} / \mathrm{ml}(\mathrm{P}<0.01)$ in the acarbose plus insulin group, and it also significantly decreased from $13.84 \pm 5.25$ to $10.63 \pm 4.31 \mathrm{pg} / \mathrm{ml}(\mathrm{P}<0.05)$ in the insulin only group (Fig. 2B). However, the addition of acarbose further reduced TNF- $\alpha$ levels as compared with the insulin group at 2 weeks ( $\mathrm{P}<0.05$; Fig. 2B).
IL-6 significantly decreased in the two groups [3.50 2.61 to $2.19 \pm 0.91 \mathrm{pg} / \mathrm{ml}$ in the acarbose plus insulin group $(\mathrm{P}<0.05)$ and from $3.72 \pm 2.70$ to $3.33 \pm 1.94 \mathrm{pg} / \mathrm{ml}$ in the insulin only group $(\mathrm{P}<0.05)$; Fig. $2 \mathrm{C}$ and $\mathrm{D}$ ]. A lower level of IL-6 was observed in the acarbose plus insulin group when compared with the insulin only group $(\mathrm{P}<0.05)$ at 2 weeks (Fig. $2 \mathrm{C})$.

IL-1 $\beta$ significantly decreased in the two groups $[22.31 \pm 6.48$ to $11.66 \pm 5.35 \mathrm{pg} / \mathrm{ml}$ in the acarbose plus insulin group $(\mathrm{P}<0.01)$ and from $22.49 \pm 7.61$ to $17.43 \pm 4.58 \mathrm{pg} / \mathrm{ml}$ in the insulin only group $(\mathrm{P}<0.05)]$ in 2 weeks. However, IL-1 $\beta$ in the acarbose plus insulin group was significantly lower than that of the insulin only group at 2 weeks $(\mathrm{P}<0.01 ;$ Fig. 2D).

Adipocytokines. The APN level marginally increased from $5,539.06 \pm 2312.45$ to $6,156.94 \pm 2797.11 \mathrm{ng} / \mathrm{ml}(\mathrm{P}>0.05)$ in the insulin only group following 2 weeks of treatment (Fig. 3A). 
Similarly, the APN level increased from $6,110.31 \pm 2485.21$ to $6,458.88 \pm 3851.47 \mathrm{ng} / \mathrm{ml}(\mathrm{P}>0.05)$ in the acarbose plus insulin group. However, no significant difference in the APN level was identified between the two groups at 2 weeks $(\mathrm{P}>0.05$; Fig. 3A). The leptin level in the acarbose plus insulin group marginally reduced from $19.11 \pm 6.15$ to $15.69 \pm 4.11 \mathrm{ng} / \mathrm{ml}$ $(\mathrm{P}>0.05)$. Similarly, the leptin level in the insulin only group decreased from $18.38 \pm 5.43$ to $16.61 \pm 3.87 \mathrm{ng} / \mathrm{ml}$ following 2 weeks of treatment $(\mathrm{P}>0.05)$. No significant difference in the level of leptin was observed between the two groups at 2 weeks ( $\mathrm{P}>0.05$; Fig. 3B).

Safety. Adverse events, consisting of digestive disorders, were reported by nine of the patients in the acarbose plus insulin group and by three of the insulin only group patients.

\section{Discussion}

In the current study, the efficacy of acarbose on oxidative stress, and lipid and inflammatory profiles in patients with T2DM receiving insulin therapy was evaluated. The addition of acarbose with insulin therapy was observed to more effectively improve oxidative stress and the inflammatory profiles of patients with T2DM when compared with patients receiving insulin therapy alone.

Acute glucose fluctuations, other than chronic hyperglycemia, during postprandial periods more significantly affect oxidative stress in patients with T2DM (8). The rapid rise in postprandial blood glucose concentration induces an over production of peroxynitrite and nitrotyrosine $(8,9,21)$. Thus, there are continued efforts aimed at suppressing postprandial hyperglycemia in patients with T2DM (22). Previous studies indicated that improved postprandial glycemic excursions smooth oxidative and nitrosative stress (23). Chiasson et al (24) reported that acarbose was able to normalize the PPG concentration in patients with impaired glucose tolerance (IGT). Furthermore, clinical trials have shown that acarbose treatment prevents cardiovascular complications in patients with T2DM and in those with IGT $(12,25)$. Studies have also demonstrated that postprandial hyperglycemia concentration results in an increase of oxidative stress in patients with T2DM (26), which is associated with endothelial dysfunction (27). Kato et al (10) suggested that acarbose enhances postprandial endothelial function by improvement of postprandial hyperglycemia. Notably, postprandial hyperglycemia as a risk factor for cardiovascular disease was evaluated by the STOP-NIDDM (12) Trial and the data indicated that acarbose treatment was associated with a $49 \%$ relative risk reduction in the development of cardiovascular events. The current study presents evidence that the improved glucose fluctuation resulting from acarbose plus insulin therapy leads to a reduction of oxidative stress in patients with T2DM.

There is also evidence that hyperglycemia contributes to the inflammation experienced by patients with T2DM. It has been demonstrated that repeated fluctuations of glucose produce increased circulating levels of inflammatory cytokines when compared with stable, high glucose levels in normal subjects (28). Daniele et al (20) demonstrated that the inflammatory score, an integrated quantity of TNF- $\alpha$, IL-6, monocyte chemoattractant protein-1, fractalkine, osteopontin and APN, is increased in patients with T2DM and correlates with hyperglycemia (20). The link between hyperglycemia, increased oxidative stress and the higher level of inflammatory cytokines was first demonstrated by Esposito et al (28) who suggested that hyperglycemia increases the levels of inflammatory cytokines via an oxidative mechanism (28). Notably, in the present study, the levels of serum inflammatory markers (Hs-CRP, IL-1 $\beta$, IL-6 and TNF- $\alpha$ ) were significantly decreased in patients with T2DM who were treated with acarbose plus insulin therapy when compared with those that received only insulin therapy, along with decreased oxidative stress levels. This may suggest that acarbose attenuates the oxidation that is caused by hyperglycemia or/and hyperinsulinemia. It was found that the level of APN, an anti-inflammatory cytokine (29), was not significantly increased in the current study.

In conclusion, the addition of acarbose to insulin therapy was associated with a reduction in oxidative stress and inflammation in patients with T2DM. However, future studies are required to clarify the underlying mechanisms.

\section{Acknowledgements}

The present study was funded by Nanjing Public Health Bureau Project (grant no. YKK11110), Nanjing Science and Technology Commission Project (grant no. 201201108) and Jiangsu Provincial Department of Science and Technology Project (grant no. BL2014010).

\section{References}

1. Bischoff $\mathrm{H}$ : The mechanism of alpha-glucosidase inhibition in the management of diabetes. Clin Invest Med 18: 303-311, 1995.

2. Krentz AJ and Bailey CJ: Oral antidiabetic agents: Current role in type 2 diabetes mellitus. Drugs 65: 385-411, 2005.

3. Meneilly GS, Ryan EA, Radziuk J, Lau DC, Yale JF, Morais J, Chiasson JL, Rabasa-Lhoret R, Maheux P, Tessier D, et al: Effect of acarbose on insulin sensitivity in elderly patients with diabetes. Diabetes care 23: 1162-1167, 2000.

4. Li FF, Xu XH, Fu LY, Su XF, Wu JD, Lu CF, Ye L and Ma JH: Influence of acarbose on plasma glucose fluctuations in insulin-treated patients with type 2 diabetes: A pilot study. Int J Endocrinol 2015: 903524, 2015.

5. The relationship of glycemic exposure (HbAlc) to the risk of development and progression of retinopathy in the diabetes control and complications trial. Diabetes 44: 968-983, 1995.

6. Klein R: Hyperglycemia and microvascular and macrovascular disease in diabetes. Diabetes Care 18: 258-268, 1995.

7. Stratton IM, Adler AI, Neil HA, Matthews DR, Manley SE, Cull CA, Hadden D, Turner RC and Holman RR: Association of glycaemia with macrovascular and microvascular complications of type 2 diabetes (UKPDS 35): Prospective observational study. BMJ 321: 405-412, 2000.

8. Monnier L, Mas E, Ginet C, Michel F, Villon L, Cristol JP and Colette C: Activation of oxidative stress by acute glucose fluctuations compared with sustained chronic hyperglycemia in patients with type 2 diabetes. JAMA 295: 1681-1637, 2006.

9. Hu Y, Liu W, Huang R and Zhang X: Postchallenge plasma glucose excursions, carotid intima-media thickness and risk factors for atherosclerosis in Chinese population with type 2 diabetes. Atherosclerosis 210: 302-306, 2010.

10. Kato T, Inoue T and Node K: Postprandial endothelial dysfunction in subjects with new-onset type 2 diabetes: An acarbose and nateglinide comparative study. Cardiovasc Diabetol 9: 12, 2010.

11. Santilli F, Formoso G, Sbraccia P, Averna M, Miccoli R, Di Fulvio P, Ganci A, Pulizzi N, Lattanzio S, Ciabattoni G, et al: Postprandial hyperglycemia is a determinant of platelet activation in early type 2 diabetes mellitus. J Thromb Haemost 8: 828-837, 2010 
12. Chiasson JL, Josse RG, Gomis R, Hanefeld M, Karasik A and Laakso M; STOP-NIDDM Trial Research Group: Acarbose treatment and the risk of cardiovascular disease and hypertension in patients with impaired glucose tolerance: The STOP-NIDDM trial. JAMA 290: 486-494, 2003.

13. Kashiwagi A, Shinozaki K, Nishio Y, Maegawa H, Maeno Y, Kanazawa A, Kojima H, Haneda M, Hidaka H, Yasuda H and Kikkawa R: Endothelium-specific activation of $\mathrm{NAD}(\mathrm{P}) \mathrm{H}$ oxidase in aortas of exogenously hyperinsulinemic rats. Am J Physiol 277: E976-E983, 1999.

14. Monnier L, Colette C, Mas E, Michel F, Cristol JP, Boegner C and Owens DR: Regulation of oxidative stress by glycaemic control: Evidence for an independent inhibitory effect of insulin therapy. Diabetologia 53: 562-571, 2010.

15. Schnell O, Mertes G and Standl E; Acarbose-Insulin Combination Study Group: Acarbose and metabolic control in patients with type 2 diabetes with newly initiated insulin therapy. Diabetes Obes Metab 9: 853-858, 2007.

16. Weng J,Li Y, Xu W, Shi L, Zhang Q, Zhu D, Hu Y,Zhou Z, Yan X, Tian H, et al: Effect of intensive insulin therapy on beta-cell function and glycaemic control in patients with newly diagnosed type 2 diabetes: A multicentre randomised parallel-group trial. Lancet 371: 1753-1760, 2008.

17. Service FJ, Molnar GD, Rosevear JW, Ackerman E, Gatewood LC and Taylor WF: Mean amplitude of glycemic excursions, a measure of diabetic instability. Diabetes 19: 644-655, 1970.

18. Ziegler R, Tubili C, Chico A, Guerci B, Lundberg E, Borchert M, Löffler A, Bloethner S, Weissmann J and Pfützner A: ProAct study: New features of insulin pumps improve diabetes management and glycemic control in patients after transition of continuous subcutaneous insulin infusion systems. Diabetes Technol Ther 15: 738-743, 2013.

19. Wu JD, Xu XH, Zhu J, Ding B, Du TX, Gao G, Mao XM, Ye L, Lee $\mathrm{KO}$ and Ma JH: Effect of exenatide on inflammatory and oxidative stress markers in patients with type 2 diabetes mellitus. Diabetes Technol Ther 13: 143-148, 2011.

20. Daniele G, Guardado Mendoza R, Winnier D, Fiorentino TV, Pengou Z, Cornell J, Andreozzi F, Jenkinson C, Cersosimo E, Federici $\mathrm{M}$, et al: The inflammatory status score including IL-6, TNF- $\alpha$, osteopontin, fractalkine, MCP-1 and adiponectin underlies whole-body insulin resistance and hyperglycemia in type 2 diabetes mellitus. Acta Diabetol 51: 123-131, 2014.
21. Ceriello A, Esposito K, Piconi L, Ihnat MA, Thorpe JE, Testa R, Boemi M and Giugliano D: Oscillating glucose is more deleterious to endothelial function and oxidative stress than mean glucose in normal and type 2 diabetic patients. Diabetes 57: 1349-1354, 2008.

22. Gallwitz B: Implications of postprandial glucose and weight control in people with type 2 diabetes: Understanding and implementing the international diabetes federation guidelines. Diabetes Care 2 (Suppl 32): S322-S513, 2009.

23. Ceriello A, Quagliaro L, Catone B, Pascon R, Piazzola M, Bais B, Marra G, Tonutti L, Taboga C and Motz E: Role of hyperglycemia in nitrotyrosine postprandial generation. Diabetes Care 25: 1439-1443, 2002.

24. Chiasson JL, Josse RG, Leiter LA, Mihic M, Nathan DM, Palmason C, Cohen RM and Wolever TM: The effect of acarbose on insulin sensitivity in subjects with impaired glucose tolerance. Diabetes Care 19: 1190-1203, 1996.

25. Hanefeld M, Cagatay M, Petrowitsch T, Neuser D, Petzinna D and Rupp M: Acarbose reduces the risk for myocardial infarction in type 2 diabetic patients: Meta-analysis of seven long-term studies. Eur Heart J 25: 10-16, 2004.

26. Ceriello A, Bortolotti N, Falleti E, Taboga C, Tonutti L, Crescentini A, Motz E, Lizzio S, Russo A and Bartoli E: Total radical-trapping antioxidant parameter in NIDDM patients. Diabetes Care 20: 194-197, 1997.

27. El Midaoui A, Wu R and de Champlain J: Prevention of hypertension, hyperglycemia and vascular oxidative stress by aspirin treatment in chronically glucose-fed rats. J Hypertens 20: 1407-1412, 2002

28. Esposito K, Nappo F, Marfella R, Giugliano G, Giugliano F, Ciotola M, Quagliaro L, Ceriello A and Giugliano D: Inflammatory cytokine concentrations are acutely increased by hyperglycemia in humans: Role of oxidative stress. Circulation 106: 2067-2072, 2002.

29. Tilg $\mathrm{H}$ and Moschen AR: Role of adiponectin and PBEF/visfatin as regulators of inflammation: Involvement in obesity-associated diseases. Clin Sci (Lond) 114: 275-288, 2008. 